\title{
Lumbar artery branches coursing vertically over the intervertebral discs of the lower lumbar spine: an anatomic study
}

\author{
Hidetoshi Nojiri ${ }^{1}(D)$ Kei Miyagawa ${ }^{1} \cdot$ Sammy Banno $^{1} \cdot$ Ikko Sakamoto $^{2} \cdot$ \\ Masato Koike $^{1} \cdot$ Mamiko Sawa $^{1} \cdot$ Yoshiyuki Iwase $^{1} \cdot$ Hiroyuki Kudo $^{3}$. \\ Tatsuo Sakai ${ }^{3} \cdot$ Kazuo Kaneko ${ }^{2}$
}

Received: 15 May 2016/Revised: 1 August 2016/Accepted: 1 August 2016/Published online: 6 August 2016

(C) The Author(s) 2016. This article is published with open access at Springerlink.com

\begin{abstract}
Purpose Bleeding from the lumbar artery is a potential complication during the transpsoas approach to the lower lumbar intervertebral discs. In this anatomic study, the morphological relationships between the branches of the lumbar artery and the lower intervertebral disc were investigated to assess the risk of injury to the branches of the lumbar segmental arteries.

Methods We studied 88 sites (86 lumbar arteries) at the third and fourth lumbar vertebrae bilaterally in 22 formalin-fixed cadavers. The branches of the lumbar artery coursing along the lateral sides of the lower intervertebral disc [muscular branch, anastomotic branch, and branch supplying the spinal nerve and plexus (BSNP)] and the iliolumbar artery running upward over the L4-5 disc were identified. Branches crossing the intervertebral discs vertically were evaluated.

Results Muscular branches with a lumen structure longer than $2 \mathrm{~cm}$ coursed vertically over the middle third of the intervertebral disc in 3 of 88 sites $(3.4 \%)$. Anastomotic branches ran downward in 13 of $88(14.8 \%)$, and iliolumbar arteries ran upward on the posterior third of the lateral sides of the disc in 2 of $88(2.3 \%)$. BSNPs ran downward through the posterior third of the disc at 18 of 88
\end{abstract}

Hidetoshi Nojiri

hnojiri@juntendo.ac.jp

1 Department of Orthopaedic Surgery, Juntendo Tokyo Koto Geriatric Medical Center, Juntendo University School of Medicine, 3-3-20 Shinsuna, Koto-ku, Tokyo 136-0075, Japan

2 Department of Orthopaedic Surgery, Juntendo University, Tokyo, Japan

3 Department of Anatomy and Life Structure, Juntendo University, Tokyo, Japan sites $(20.5 \%)$. Overall, the arterial branches coursed vertically over the posterior third of the lateral sides of the intervertebral discs in approximately $30 \%$ of subjects.

Conclusions Lumbar artery branches coursed vertically over the middle third and the posterior third of the lateral sides of the intervertebral discs in approximately 3 and $30 \%$ of subjects, respectively.

Keywords Anatomy · Lumbar artery · Branch · Transpsoas approach $\cdot$ Vascular injury

\section{Introduction}

The lower lumbar spine is a major site of pathology in spine disorders, and surgery is frequently performed in this area. Anterior spinal interbody fusion is an effective treatment method for degenerative spine diseases and spinal deformities [1,2], and recent methodological and technical innovations in spine surgery have rendered the anterior spinal approach safe. In particular, the lateral approach to anterior spinal fusion through the psoas muscle, extreme lateral interbody fusion (XLIF) [3], is becoming widely performed.

Intervertebral discs are composed of avascular tissue; they are safely and easily accessible and are, therefore, considered reasonable sites for spinal fusion. They can be approached from anteriorly, laterally, transforaminally, or posteriorly. Vascular injury can be an unexpected complication during the transpsoas approach to accessing the intervertebral disc laterally, [4-8] but because the lumbar artery, rather than the large vessels, may be a more frequent site of bleeding during the transpsoas approach, it should be understood in detail. However, there are few anatomic studies of the morphologic relationship between the 
branches of the lumbar artery and the intervertebral disc. In this study, we investigated the morphology of the branches of the lumbar artery at the lateral sides of the intervertebral disc and its clinical importance.

\section{Materials and methods}

We studied 88 sites (86 lumbar arteries; 2 sites demonstrated absence of the artery) at the third and fourth lumbar vertebrae bilaterally in 22 formalin-fixed cadavers. Specimens with transitional vertebrae were excluded. To identify each lumbar artery from the vertebra through the vertebral foramen, lumbar spines were divided into right and left at the midline of the vertebral bodies and placed in the lateral position. The third and fourth lumbar arteries at the L3 and L4 levels were exposed by carefully removing the psoas muscle and fatty tissues. The branches of the lumbar artery crossing the lateral sides of the intervertebral discs, including muscular branches, anastomotic branches, and branches supplying the spinal nerve and plexus (BSNP), were visualized. The iliolumbar artery running upward on

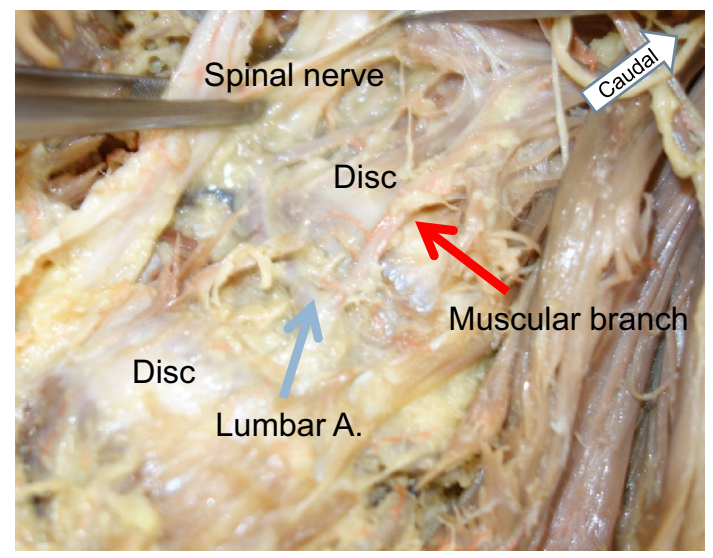

Fig. 1 Photograph showing the muscular branch coursing vertically over the middle of the L4-5 intervertebral disc the L4-5 intervertebral disc was also identified. The capillary branches and muscular branches extending into the psoas muscle shortly after the bifurcation were excluded. The specimens were evaluated for the presence of branches coursing vertically over the intervertebral discs.

\section{Results}

Muscular branches having a lumen structure longer than $2 \mathrm{~cm}$ crossed vertically over the middle third of the intervertebral disc in 3 of 88 sites (3.4\%) (Fig. 1). Anastomotic branches flowing into the caudal adjacent foramen or connecting with the iliolumbar arteries ran downward along the posterior third of the intervertebral disc in 13 of 88 sites $(14.8 \%$,) (Fig. 2a). Iliolumbar arteries ran upward along the L4 spinal nerve on the L4-5 intervertebral disc in 2 of 88 sites $(2.3 \%$ ) (Fig. 2b).

A BSNP was seen in 25 of 44 sites $(56.8 \%)$ at L3 and in 40 of 44 sites $(90.9 \%)$ at L4, or 65 of 88 (73.9\% overall). The BSNPs originated at the lumbar artery and then ran downward, either through the posterior third of the intervertebral disc before the anterior edge of the spinal nerve, or at an extraforaminal site behind the anterior edge of the spinal nerve. The former pattern was found in 18 of 65 branches $(27.7 \%$ ) (Fig. 3a) and the latter in 47 of 65 branches $(72.3 \%$ ) (Figs. 3b, 4a). According to these results, the branches of the arteries crossed vertically on the posterior third of the intervertebral disc in 8 of 44 sites (18.2\%) at L3 and 18 of 44 sites $(40.9 \%)$ at L4, or 26 of 88 sites (29.5\% overall) (Table 1; Fig. 4b).

\section{Discussion}

XLIF is a novel, minimally invasive method in spinal fusion surgery for which good biomechanical effects have been reported. However, an incidence of vascular complications of $0.10 \%$ was revealed in a survey of 13,004
Fig. 2 Photographs showing a anastomotic branch and b iliolumbar artery coursing vertically over the posterior third of the intervertebral disc

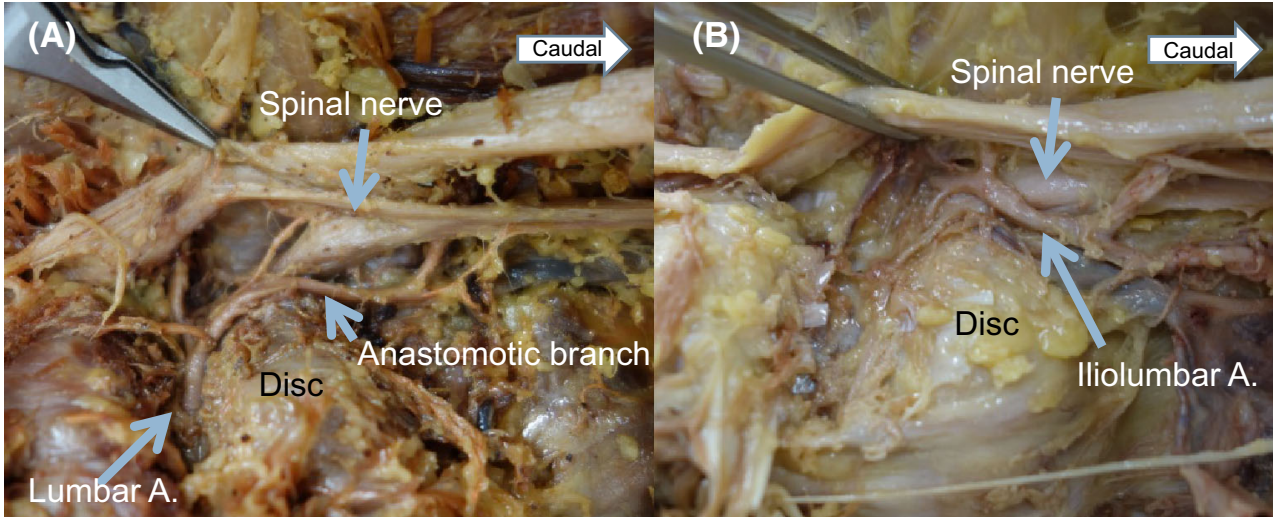


Fig. 3 BSNPs originating from the lumbar artery. Difference between sites in which the BSNP courses a along the posterior third of the intervertebral disc and b extraforaminally behind the anterior edge of the spinal nerve. BSNP, branch supplying the spinal nerve and plexus

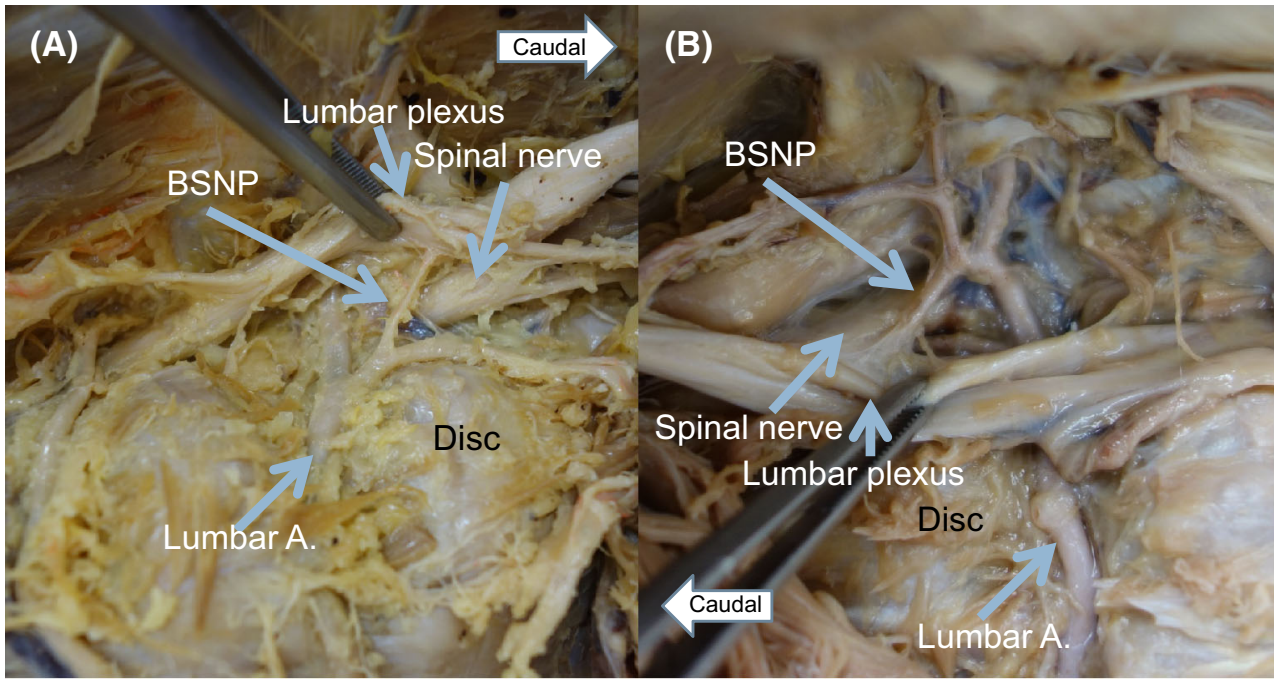

(A)

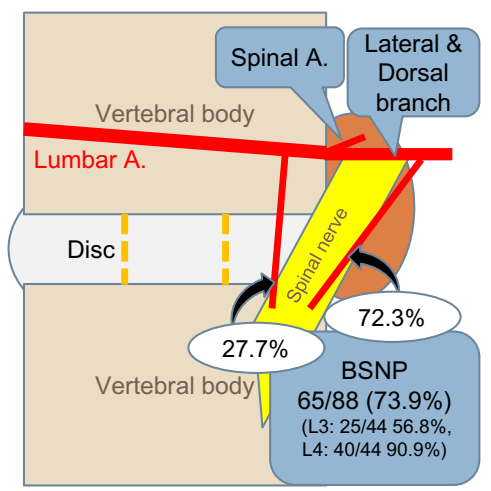

(B)

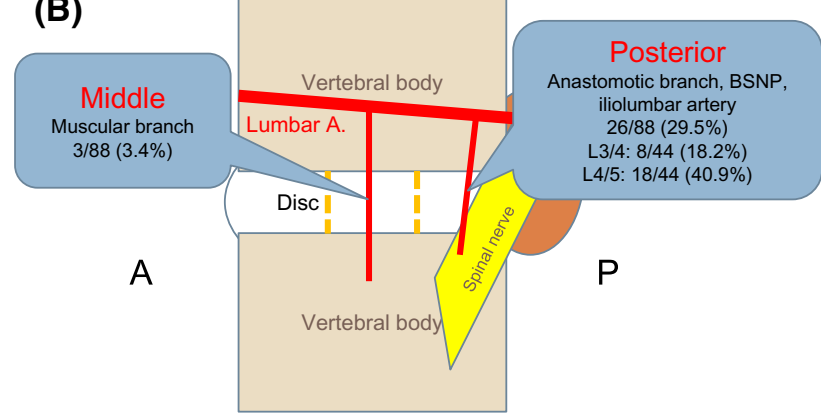

Fig. 4 Schemata depicting a BSNPs and their locations running vertically in front of or behind the anterior edge of the spinal nerve; and $\mathbf{b}$ branches of the lumbar artery running down the middle of the disc and the posterior third of the disc laterally. BSNP branch supplying the spinal nerve and plexus

patients whose procedures were performed by an experienced surgeon [8]. A few studies have demonstrated a safe zone for avoiding injuries of the retroperitoneal large vessels, which can be identified using preoperative magnetic resonance imaging (MRI) to assess the relative positions of the adjacent neurovascular structures with respect to the each intervertebral disc level $[9,10]$.
Although injury to large vessels must always be prevented, injury to the lumbar artery occurs more frequently than injury to large vessels during the transpsoas approach [5]. Furthermore, few reports have demonstrated the presence and precise morphology of the branches of the lumbar artery at the extraforaminal area at the disc level $[11,12]$. The results of the present study clearly demonstrate the existence of branches of the lumbar artery running along the discs.

Although the anatomy and blood supply of the sciatic nerve have been described in detail [13], there have been no detailed anatomic studies of the branches of the lumbar artery and blood supply to the lumbar plexus. Arslan et al. observed that the anastomotic arteries ran vertically approximately $4 \mathrm{~mm}$ anterior to the base of the transverse process [12]. In an angiographic study of lumbar artery anastomoses, Ratcliffe et al. demonstrated that this anastomosis exists at all levels but is most pronounced between the arteries at L4 and L5, suggesting that the risk of bleeding was higher during surgery involving L4 and L5 than at other levels [14]. Tezuka et al. showed various vascular patterns around the lower lumbar spine in their anatomical analysis using contrast-enhanced computed tomography (CT) and identified several variations of distributing arteries from the lumbar artery to the posterior element of L4-5 [15]. Our study also revealed that the branches of the lumbar artery appeared more frequently on the posterior third of the L4-5 intervertebral disc than at the L3-4 level.

Our study also suggests that care should be taken when approaching disc through the psoas muscle and performing contralateral disc excision through the disc space because intraoperative bleeding and postoperative retroperitoneal hematoma caused by lumbar artery injury have been reported $[5,6]$. Further, posterior disc penetration, posterior 
Table 1 Summary of arterial branches coursing vertically over the intervertebral discs of the lower lumbar spine

\begin{tabular}{|c|c|c|c|c|c|c|}
\hline & \multirow{2}{*}{$\begin{array}{l}\text { Muscular } \\
\text { branch }\end{array}$} & \multirow{2}{*}{$\begin{array}{l}\text { Anastomotic } \\
\text { branch }\end{array}$} & \multirow{2}{*}{$\begin{array}{l}\text { Iliolumbar } \\
\text { artery }\end{array}$} & \multicolumn{2}{|l|}{ BSNP } & \multirow{2}{*}{$\begin{array}{l}\text { Running on posterior } \\
1 / 3 \text { of disc }\end{array}$} \\
\hline & & & & Presence & Through the disc & \\
\hline L3 (44 sites) & 1 & 4 & & $25(56.8 \%)$ & $6(13.6 \%)$ & $8(18.2 \%)$ \\
\hline L4 (44 sites) & 2 & 9 & 2 & $40(90.9 \%)$ & $12(27.3 \%)$ & $18(40.9 \%)$ \\
\hline Total (88 sites) & $3(3.4 \%)$ & $13(14.8 \%)$ & $2(2.3 \%)$ & $65(73.9 \%)$ & $18(20.5 \%)$ & $26(29.5 \%)$ \\
\hline
\end{tabular}

Data expressed as $n(\%)$

cage placement, and oblique cage insertion can be risk factors not only for neurological complications due to spinal nerve injuries [16, 17], but also for vascular complications. These studies suggest the importance of preoperative MRI or contrast-enhanced computed tomography to detect abnormal arteries and that it is essential to prepare for unexpected bleeding from the branches of the lumbar arteries during spine surgery via the transpsoas approach. The findings of the present anatomic study bring to spine surgeons an awareness of the existence of the branches of the lumbar artery coursing vertically over the intervertebral discs, which is important when performing spinal fusion surgeries via the transpsoas approach.

This study has several limitations. First, this anatomical study is based on gross observation of branches that have a lumen structure. Microstructural arteries must exist with greater frequency than that shown in this analysis. Second, the study sample was small, and it is possible that there are other variations in the morphology of the branches of the lumbar artery.

\section{Compliance with ethical standards}

\section{Conflict of interest None.}

Open Access This article is distributed under the terms of the Creative Commons Attribution 4.0 International License (http://crea tivecommons.org/licenses/by/4.0/), which permits unrestricted use, distribution, and reproduction in any medium, provided you give appropriate credit to the original author(s) and the source, provide a link to the Creative Commons license, and indicate if changes were made.

\section{References}

1. Mayer HM (1997) A new microsurgical technique for minimally invasive anterior lumbar interbody fusion. Spine (Phila Pa 1976) 22:691-699 (discussion 700)

2. Kaneda K, Shono Y, Satoh S, Abumi K (1996) New anterior instrumentation for the management of thoracolumbar and lumbar scoliosis. Application of the Kaneda two-rod system. Spine (Phila Pa 1976) 21:1250-1261 (discussion 1261-1252)

3. Ozgur BM, Aryan HE, Pimenta L, Taylor WR (2006) Extreme lateral interbody fusion (XLIF): a novel surgical technique for anterior lumbar interbody fusion. Spine J 6:435-443. doi:10. 1016/j.spinee.2005.08.012
4. Buric J, Bombardieri D (2015) Direct lesion and repair of a common iliac vein during XLIF approach. Eur Spine J. doi:10. 1007/s00586-015-4134-4

5. Kueper J, Fantini GA, Walker BR, Aichmair A, Hughes AP (2015) Incidence of vascular complications during lateral lumbar interbody fusion: an examination of the mini-open access technique. Eur Spine J 24:800-809. doi:10.1007/s00586-015-3796-2

6. Peiró-García A, Domínguez-Esteban I, Alía-Benítez J (2015) Retroperitoneal hematoma after using the extreme lateral interbody fusion (XLIF) approach: presentation of a case and a review of the literature. Rev Esp Cir Ortop Traumatol. doi:10.1016/j. recot.2014.12.006

7. Santillan A, Patsalides A, Gobin YP (2010) Endovascular embolization of iatrogenic lumbar artery pseudoaneurysm following extreme lateral interbody fusion (XLIF). Vasc Endovasc Surg 44:601-603. doi:10.1177/15385744410374655

8. Uribe JS, Deukmedjian AR (2015) Visceral, vascular, and wound complications following over 13,000 lateral interbody fusions: a survey study and literature review. Eur Spine J 24(Suppl 3):386-396. doi:10.1007/s00586-015-3806-4

9. Hu WK, He SS, Zhang SC, Liu YB, Li M, Hou TS, Ma XL, Wang J (2011) An MRI study of psoas major and abdominal large vessels with respect to the X/DLIF approach. Eur Spine J 20:557-562. doi:10.1007/s00586-010-1609-1

10. Regev GJ, Chen L, Dhawan M, Lee YP, Garfin SR, Kim CW (2009) Morphometric analysis of the ventral nerve roots and retroperitoneal vessels with respect to the minimally invasive lateral approach in normal and deformed spines. Spine (Phila Pa 1976) 34:1330-1335. doi:10.1097/BRS.0b013e3181a029e1

11. Caglar S, Dolgun H, Ugur HC, Torun F, Attar A, Uz A, Tekdemir I, Elhan A (2004) Extraforaminal lumbar arterial anatomy. Surg Neurol 61:29-33 (discussion 33)

12. Arslan M, Comert A, Acar HI, Ozdemir M, Elhan A, Tekdemir I, Tubbs RS, Ugur HC (2011) Surgical view of the lumbar arteries and their branches: an anatomical study. Neurosurgery 68:16-22. doi:10.1227/NEU.0b013e318205e307 (discussion 22)

13. Kanawati AJ (2014) Variations of the sciatic nerve anatomy and blood supply in the gluteal region: a review of the literature. ANZ J Surg 84:816-819. doi:10.1111/ans.12675

14. Ratcliffe JF (1980) The arterial anatomy of the adult human lumbar vertebral body: a microarteriographic study. J Anat 131:57-79

15. Tezuka F, Sakai T, Nishisho T, Takata Y, Higashino K, Takao S, Harada M, Sairyo K (2016) Variations in arterial supply to the lower lumbar spine. Eur Spine J. doi:10.1007/s00586-016-4427-2

16. Taher F, Hughes AP, Lebl DR, Sama AA, Pumberger M, Aichmair A, Huang RC, Cammisa FP, Girardi FP (2013) Contralateral motor deficits after lateral lumbar interbody fusion. Spine (Phila Pa 1976) 38:1959-1963. doi:10.1097/BRS.0b013e3182a463a9

17. Papanastassiou ID, Eleraky M, Vrionis FD (2011) Contralateral femoral nerve compression: an unrecognized complication after extreme lateral interbody fusion (XLIF). J Clin Neurosci 18:149-151. doi:10.1016/j.jocn.2010.07.109 